\title{
Development of a computer program for underground mine stope optimisation using a heuristic algorithm
}

\author{
F Sotoudeh Shahrood University of Technology, Iran \\ R Kakaie Shahrood University of Technology, Iran \\ M Ataei Shahrood University of Technology, Iran
}

\begin{abstract}
Stope layout optimisation improves the economic potential of any underground mining operation and maximises profitability over mine life. A limited number of algorithms are available for underground stope layout optimisation. However, the available algorithms do not guarantee an optimal solution in three-dimensional space. In this paper, existing algorithms for underground stope layout optimisation were reviewed and a computer program called Stope Layout Optimizer 3D (SLO3D) was developed as a C\# user interface to implement a heuristic algorithm for optimisation of underground stope boundaries. SLO3D provides an interactive environment to define and edit important parameters related to the stope layout optimisation, including block model parameters, stope geometry, and economic factors. Finally, an example is presented to demonstrate the implementation of algorithm with different stope limits and selection type strategies.
\end{abstract}

Keywords: underground mining, stope layout optimisation, heuristic algorithms, SLO3D

\section{Introduction}

Hard rock mining is divided into two major categories: surface mining and underground mining. Open pit mining as a form of surface mining is the most popular and economically efficient method when the ore is located close to the surface. Underground mining is suitable for deep deposits located in sensitive areas with high reclamation costs associated with open pit operation. Underground mining methods are higher risk and more complex than surface mining, and have higher mining costs (O'Sullivan \& Newman 2015). Table 1 shows a comparison of these two mining methods.

Table 1 Comparison of open pit mining and underground mining (O'Sullivan \& Newman 2015)

\begin{tabular}{lll}
\hline Attribute & Open pit mining & Underground mining \\
\hline Complexity & Less complex & More complex \\
Waste mining & Very high & Low \\
Stockpiling ore & Yes & No \\
Environmental disruption & Large footprint & Small footprint \\
Safety & Relatively safe & High risk \\
Extraction costs & Low & High \\
Reclamation costs & High & Relatively low \\
\hline
\end{tabular}

A variety of methods have been proposed in order to find the optimum limit of open pit mines (Ovanic \& Young 1995). Underground mine optimisation has attracted more attention in the last 15 years. Less effort has been done in the field of underground mining and only a few algorithms are available for economic 
optimisation of underground stope boundaries (Topal \& Sens 2010). The major reasons for the lack of research in stope layout optimisation include (Mirzaeian \& Ataee-Pour 2011):

- Generality: The existing underground mining methods are numerous; development of a general and common optimisation algorithm for all mining methods is difficult.

- Complexity: Due to various restrictions and conditions of underground mining optimisation; geological, geomechanical and economical modelling of these parameters are more complex.

- Acceptability: Computer programs have contributed to the automatic design of mining areas. However, traditional methods and practices have a greater adherence to general designs by software, especially in Iran.

Due to computational complexity and size of the problem, most of the proposed algorithms in this area work in two-dimensional (2D) space. Few computer packages have been developed to determine and optimise underground stope layout in three-dimensional (3D) space. In this paper, a computer program will be presented, named Stope Layout Optimizer 3D (SLO3D) based on a heuristic algorithm. It is written in the C\# programming language. A step-by-step description of this program is outlined in this paper. This computer program has successfully been applied to determine the location of all stopes into an actual copper deposit.

\section{$2 \quad$ Literature review}

The existing algorithms for underground stope layout optimisation can be classified in two groups: level-oriented and field-oriented. The level-oriented algorithms such as dynamic programming (Riddle 1977), branch and bound (Ovanic \& Young 1999), optimum limit integrated probable stope (OLIPS) algorithm (Jalali \& Ataee-Pour 2004; Jalali et al. 2007a); mixed integer programming (Grieco \& Dimitrakopoulos 2007), Greedy (Jalali \& Hosseini 2009), and global optimisation for underground mining area (GOUMA) algorithm (Jalali et al. 2016) are applied on a level or panel. In contrast, in the field-oriented algorithms, the economic value of each block is considered as a constant value and the determination of underground mining limits takes place on the entire mining area before dividing the mining area into levels or panels. Floating stope method (Alford 1995), maximum value neighbourhood (MVN) algorithm (AtaeePour 2000, 2005), multiple pass floating stope process (Carwse 2001), heuristic approaches (Topal \& Sens 2010; Sandanayake et al. 2015a, b), network flow method (Bai et al. 2013, 2014) and octree-division algorithm (Cheimanoff et al. 1989) were developed in this manner. Most of the previously proposed algorithms relied on simplification of a large and complex problem. For instance, a 3D problem was converted to a 2D problem. In the following sections, available computer programs for underground stope layout optimisation in 2D and 3D space are discussed. Table 2 shows the summary of the proposed computer programs in underground stope layout optimisation.

Table 2 Summary of the proposed computer programs in underground stope layout optimisation

\begin{tabular}{llllll}
\hline Computer program & Year & Algorithm & \multicolumn{2}{l}{ Dimension } & Mining method Optimality \\
\hline Fortran (Riddle 1977) & 1977 Riddle & 2D & Block caving & No \\
Datamine (Alford 1995) & 1995 Floating stope & 3D & All & No \\
LINGO-CPLEX (Ovanic \& Young 1999) & 1999 & Branch and bound & 1D & All & Yes \\
SLO (Ataee-Pour 2000) & 2000 MVN & 3D & All & No \\
SBO (Jalali et al. 2007a) & 2007 OLIPS & 2D & All & Yes \\
MATLAB (Topal \& Sens 2010) & 2010 Heuristic algorithm & 3D & All & No \\
GOUMA-CP (Jalali et al. 2016) & 2016 GOUMA & 2D & All & Yes \\
\hline
\end{tabular}




\subsection{Dynamic programming}

Riddle (1977) proposed an algorithm based on dynamic programming that was an extension of 3D dynamic programming method for ultimate open pit optimisation that had been developed by Johnson and Sharp in 1971 (Johnson \& Sharp 1971). The algorithm was written in Fortran and implemented on hypothetical economical block models. This algorithm defines the stope boundaries for block caving operations. The major drawback of this algorithm is that it is only able to define stope boundaries in 2D space and optimality is not guaranteed in 3D space.

\section{$2.2 \quad$ Floating stope}

Alford (1995) developed a floating stope method to determine stope boundaries for ore blocks within a resource block model. During the process of this algorithm a stope is floated with the entire block model with a specified origin and an increase in three-dimensional space. Based on this algorithm, Datamine software was presented by a company with the same name (Datamine 1995). The major problem of this method is producing overlapping stopes where some stopes share high-grade blocks (Alford et al. 2007).

\subsection{Branch and bound}

A mathematical programming technique was developed by Ovanic \& Young (1999). Mixed integer programming (MIP), in combination with piecewise linear function, optimise the origin and last location for mining for an entire row or mining panel. The MIP approach is applied with a special kind of variable named 'Special Ordered Sets Types 2' (SOS2) to determine an optimum mining limit. There are many programs to solve mathematical problems, especially branch and bound techniques including LINGO, MPS and GAMS/CPLEX packages.

\subsection{Maximum value neighbourhood}

Ataee-Pour (2000) introduced MVN as a heuristic approach based on stope/block and the order of neighbourhood that are restricted by the mine geometry constraints. Different sets of stopes are provided with different starting points for the algorithm which does not generate a mineable stope shape. Ataee-Pour (2000) developed a computer program named Stope Limit Optimizer (SLO) for stope limit optimisation in 3D space.

\subsection{OLIPS}

Jalali et al. (2007b) developed the OLIPS algorithm based on the dynamic programming method. This algorithm complies with all technical and geometric constraints and provides mathematical proof. OLIPS has two major steps. At the first step, a conventional economic model of mining panel is constructed. Then, in the second step, the probable stope economic model and integrated probable stope economic model are derived from conventional model. Based on OLIPS algorithm, a computer program named Stope Boundary Optimizer (Jalali et al. 2007b) was developed and validated by 2D hypothetical models.

\subsection{Topal and Sens heuristic approach}

Topal and Sens (2010) introduced a heuristic algorithm to optimise underground stope layout with different stope sizes and strategies in 3D space. During the optimisation, all stopes with specified height, width and length are generated based on their economic values in the MATLAB software. The major drawback of this approach is selecting stopes in descending order while removing overlapping stopes.

\subsection{GOUMA}

Jalali et al. (2016) presented a new comprehensive algorithm called GOUMA. The value of underground mining area blocks vary with geometry and location of the panel or level. So the algorithm runs on a special model named 'Variable Value Economic Model' (VVEM). For easy use of this algorithm in large-scale problems, a computer program was written in C++ programming language named GOUMA-CP (Jalali et al. 2016). 


\section{SLO3D computer program}

In order to facilitate the implementation of a heuristic algorithm previously developed by Sandanayake et al. (2015a) with some strategies that have been added to the process of this algorithm, a user-friendly interface (UI) computer program was developed in C\# and SQL-Server programming language named SLO3D. The main difference between this computer program and other programs and software tools is the kind of algorithm used. As shown in Figure 1, this computer program has three main steps: block economic value (BEV) producer, stope generator and stope layout optimiser. After defining the block economic model using economic parameters in the first step, the algorithm generates all possible stopes in an economic block model considering the stope dimension in 3D space. After that, the algorithm generates a family of non-overlapping stopes over all possible stopes and selects the highest economic value as an optimal solution. For large and complex problems, to save solution time, three new probabilistic strategies have been added to this algorithm with stope layout optimisation performed in the third step.

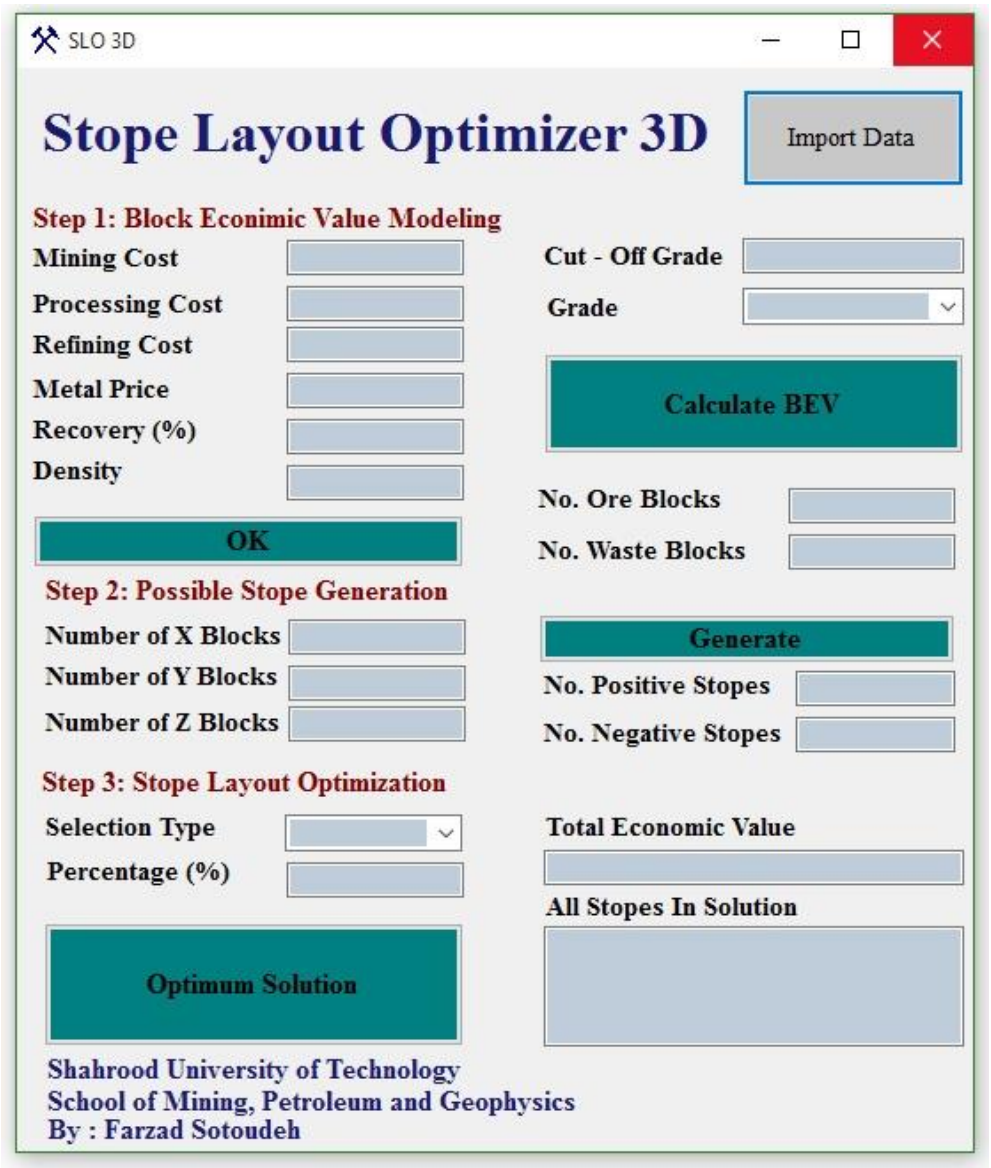

Figure 1 Stope Layout Optimizer 3D interface

\subsection{Block economic value}

A grade block model with regularised dimension as the input file must be created in Microsoft Excel format before running the program. The input file structure consists of seven major columns, similar to a spreadsheet shown in Figure 2; including the coordinate of a regularised block (XC, YC and ZC), block dimension (XINC, YINC and ZINC), grade of a block (percent or gram per tonne), value of a block (BEV (USD)), density (tonne $/ \mathrm{m}^{3}$ ), total weight and metal weight of every block. After importing the input file by clicking on the specified button named 'Import Data', the user should import economic factors such as mining cost $\left(C_{m}\right)$, processing cost $\left(C_{p}\right)$, refining cost $(R)$, metal price $(P)$, grade $(g)$, weight of a block $(T)$ and recovery $(\mathrm{Y})$. Then, with the cut-off grade defined, blocks below the cut-off grade are termed as waste blocks. After clicking on the 'Calculate BEV' button, the grade block model is converted to an economic 
model based on Equation 1 and the number of ore and waste blocks with consideration given to the cut-off grade all reported.

$$
\mathrm{BEV}=\left\{(\mathrm{P}-\mathrm{R}) \times \mathrm{g} \times \mathrm{Y}-\left(\mathrm{C}_{\mathrm{m}}+\mathrm{C}_{\mathrm{p}}\right)\right\} \times \mathrm{T}
$$

\begin{tabular}{|c|c|c|c|c|c|c|c|c|c|c|c|}
\hline Block & $X C$ & YC & $\mathrm{ZC}$ & $\mathrm{XINC}(\mathrm{m})$ & $\mathrm{XINC}(\mathrm{m})$ & $\mathrm{XINC}(\mathrm{m})$ & Grade (\%) & density (ton/m3) & BEV (\$) & Block Weight & Metal Weight \\
\hline 1 & 3348413 & 223248 & 1525.5 & 5 & 5 & 5 & 0.0192559 & 2.54 & & & \\
\hline 2 & 3348413 & 223248 & 1530.5 & 5 & 5 & 5 & 0.0409784 & 2.54 & & & \\
\hline 3 & 3348413 & 223248 & 1535.5 & 5 & 5 & 5 & 0.021165 & 2.54 & & & \\
\hline 4 & 3348413 & 223248 & 1540.5 & 5 & 5 & 5 & 0.0099024 & 2.54 & & & \\
\hline 5 & 3348413 & 223248 & 1545.5 & 5 & 5 & 5 & 0.021478 & 2.54 & & & \\
\hline
\end{tabular}

Figure 2 Input file structure before running program (Excel format)

\subsection{Stope generation}

In this step, all possible stopes with specified dimensions are generated based on the underground mining method and geotechnical stability parameters. By clicking on the 'Generate' button, the algorithm specifies the origin of the economic block model $\left(i^{\prime} j^{\prime} k^{\prime}\right)$. Then, assuming that the block increases in size increments in $X, Y$, and $Z$ directions as stope dimension parameters, the last stope block $\left(i^{\prime \prime} j^{\prime \prime} k^{\prime \prime}\right)$ is determined. The constructed stope is floated through the economic model and all possible stopes are generated based on two conditions that are shown in Equations 2 and 3.

$$
\begin{gathered}
\left(i^{\prime}, j^{\prime}, k^{\prime}\right) \leq(i, j, k) \leq\left(i^{\prime \prime}, j^{\prime \prime}, k^{\prime \prime}\right) \\
\left(i^{\prime} \leq i_{\max }, j^{\prime} \leq j_{\max }, k^{\prime} \leq k_{\max }\right)
\end{gathered}
$$

The ( $i_{\max } j_{\max } k_{\max }$ ) as shown in Equation 3 is the maximum stope block ( $\mathrm{i} j \mathrm{k}$ ) within the economic model. The average grade of each stope is calculated by summing the grade of each block within the stope and dividing this by the total number of blocks within the stope. Also, the economic value of each stope is calculated by summing the values of all the blocks. The output file structure consists of seven major columns including (Figure 3): Stope ID, Stope Dimension in X, Y and Z direction (XINC, YINC and ZINC), Stope Grade (percent),

\begin{tabular}{|c|c|c|c|c|c|c|c|c|c|c|c|c|c|}
\hline Stope ID & $\mathrm{XINC}(\mathrm{m})$ & $\mathrm{YINC}(\mathrm{m})$ & $\mathrm{ZINC}(\mathrm{m})$ & Grade (\%) & $\operatorname{SEV}(\$)$ & TotalWeight (ton) & MetalWeight (gram) & $X$-Origin & -Origin & Z-Origin & $\mathrm{X}$-Last & Y-Last & Z-Last \\
\hline 1 & 15 & 15 & 15 & 0.45056 & -2320.9109 & 8572.5 & 38624240.76 & 1 & 1 & 1 & 3 & 3 & 3 \\
\hline 2 & 15 & 15 & 15 & 0.425464 & -23862.393 & 8572.5 & 36472888.57 & 1 & 1 & 2 & 3 & 3 & 4 \\
\hline 3 & 15 & 15 & 15 & 0.363886 & -61263.955 & 8572.5 & 31194117.89 & 1 & 1 & 3 & 3 & 3 & 5 \\
\hline 4 & 15 & 15 & 15 & 0.521916 & 36243.4358 & 8572.5 & 44741242.88 & 1 & 1 & 4 & 3 & 3 & 6 \\
\hline 5 & 15 & 15 & 15 & 0.451764 & -7337.854 & 8572.5 & 38727436.04 & 1 & 1 & 5 & 3 & 3 & 7 \\
\hline
\end{tabular}
Stope Economic Value (SEV), Total Weight, Metal Weight and identifier of origin and last block of each possible stope. Finally, based on the SEV column, the number of positive and negative stopes are reported.

Figure 3 Output file structure after generating all possible stopes

\subsection{Stope layout optimisation}

In order to determine the optimum location of underground stopes, all possible sets of non-overlapping stopes are generated according to the algorithm shown in Figure 4. For this purpose, all negative stopes generated in the previous step are removed and positive stopes imported to the algorithm. Two major null family of sets, $S_{T}$ and $S_{O}$, are created. $S_{T}$ is all possible sets of non-overlapping stopes that are generated during the algorithm and $\mathrm{S}_{\mathrm{O}}$ is a unique derived set of $\mathrm{S}_{\mathrm{T}}$. During the processing of the algorithm, each stope is compared with all stopes within any set of non-overlapping stopes $\left(S_{p}\right)$. If the imported stope does not overlap with other stopes, all stopes are combined and a new set of non-overlapping stopes are created $\left(S_{\text {pnew }}\right)$. This process iterates until all positive stopes have participated in the algorithm. Finally, the high value of non-overlapping stope sets is selected as the optimum solution. 


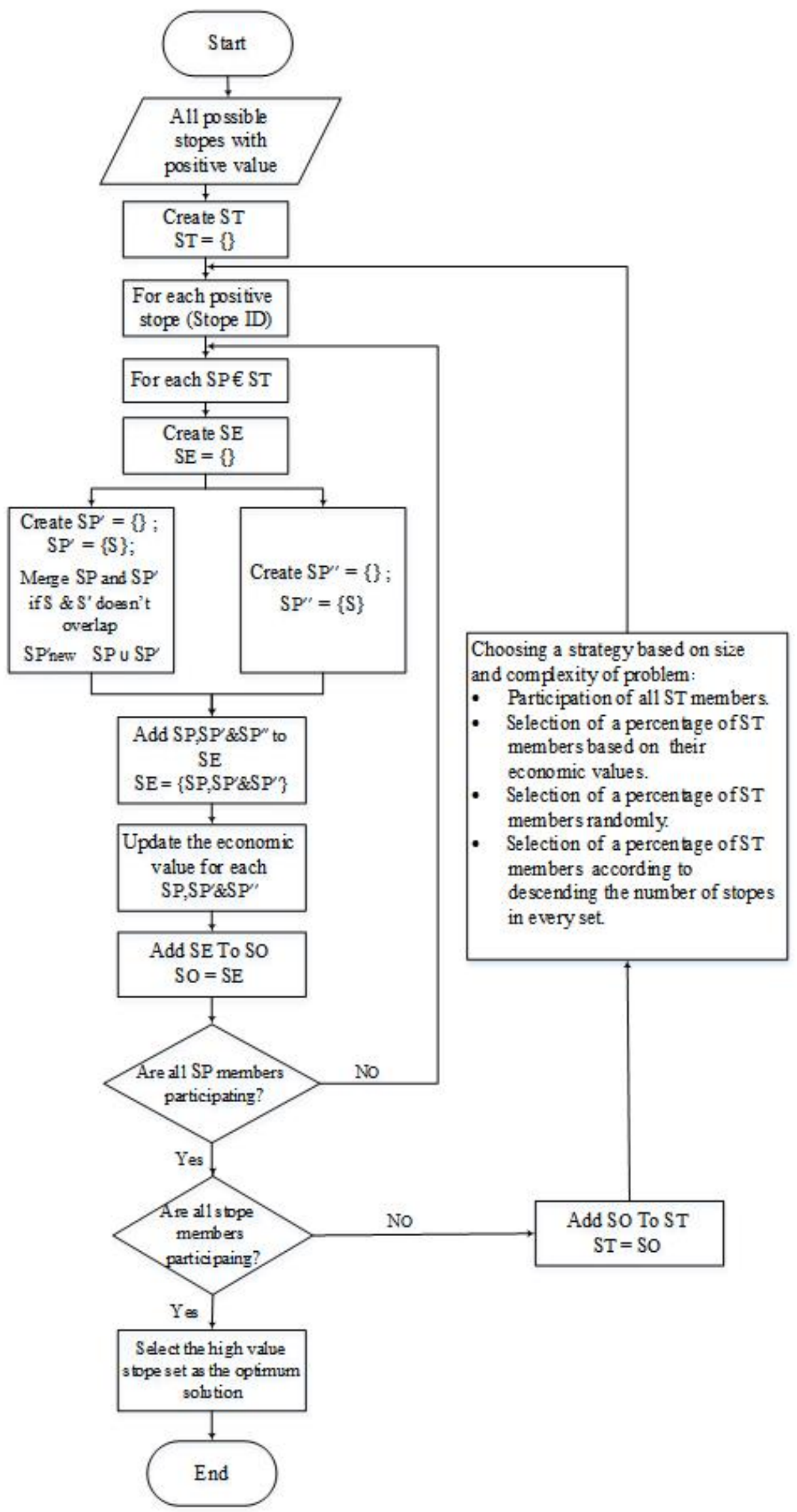

Figure 4 Revised stope layout optimisation algorithm after Sandanayake et al. (2015a) 
In large and complex problems, the sets of non-overlapping stopes $\left(\mathrm{S}_{\mathrm{p}}\right)$ are infinite. So the solution time increases exponentially. To overcome this problem, three strategies have been added to this algorithm. The first strategy is sorting of all sets ( $\mathrm{S}_{T}$ members) according to their economic value to the lowest value and selecting a percentage of the sorted collection. The major drawback of the first strategy is removing some stope sets with low economic value. In this strategy, the possibility of the combination of removed sets and other stopes to derive a set with a higher total value is discarded. Owing to this disadvantage, a second strategy with a probabilistic background was proposed.

- Selecting a percentage of $\mathrm{S}_{\mathrm{T}}$ members randomly and frequently.

- Selecting a percentage of $\mathrm{S}_{\mathrm{T}}$ members according to the descending number of stopes in each set.

As shown in Figure 1, the user should define the percentage of selection in the case of using a specified strategy amongst three strategies. By clicking on 'Optimum Solution', the total economic value of the underground layout and stopes' IDs in the mining area is reported.

\section{$4 \quad$ Application of SLO3D}

\subsection{Orebody modelling}

To introduce the capability of the SLO3D program, it was applied on an actual copper deposit located in southeast Iran. The study deposit is a copper vein with a thickness of $20 \mathrm{~m}$, a 400-m length in a longitudinal direction and reaching $100 \mathrm{~m}$ in the vertical direction (Table 3). Datamine software was used to generate an orebody model and produced 6,400 blocks of which 2,259 are oreblocks according to the cut-off grade. All blocks are $5 \times 5 \times 5 \mathrm{~m}$ in size. All blocks were estimated according to exploration and information data. The output files retrieved from the Datamine software contain the block centre coordinate, density and average grade of each block and prepared as an input file for SLO3D. A horizontal section of the grade distribution for the entire block model is shown in Figure 5. Economic parameter assumptions for converting the geological model to an economic model (BEV) are provided in Table 4. The values of all blocks calculated were based on these assumptions. Consequently, the range of economic value variation was from USD -994,234 to 2,763,576.

Table 3 The coordinates of study area

\begin{tabular}{lll}
\hline Direction & Minimum & Maximum \\
\hline$X$ & 3348410 & 3348810 \\
$Y$ & 223245 & 223265 \\
$Z$ & 1523 & 1623 \\
\hline
\end{tabular}

Table 4 Economic parameters for optimisation

\begin{tabular}{ll}
\hline Parameter & Value \\
\hline Mining (USD/tonne) & 20 \\
Processing cost (USD/tonne) & 10 \\
Refining cost (USD/tonne) & 90 \\
Copper price(USD/tonne) & 6,500 \\
Recovery (\%) & 90 \\
Cut-off grade (\%) & 0.52 \\
\hline
\end{tabular}




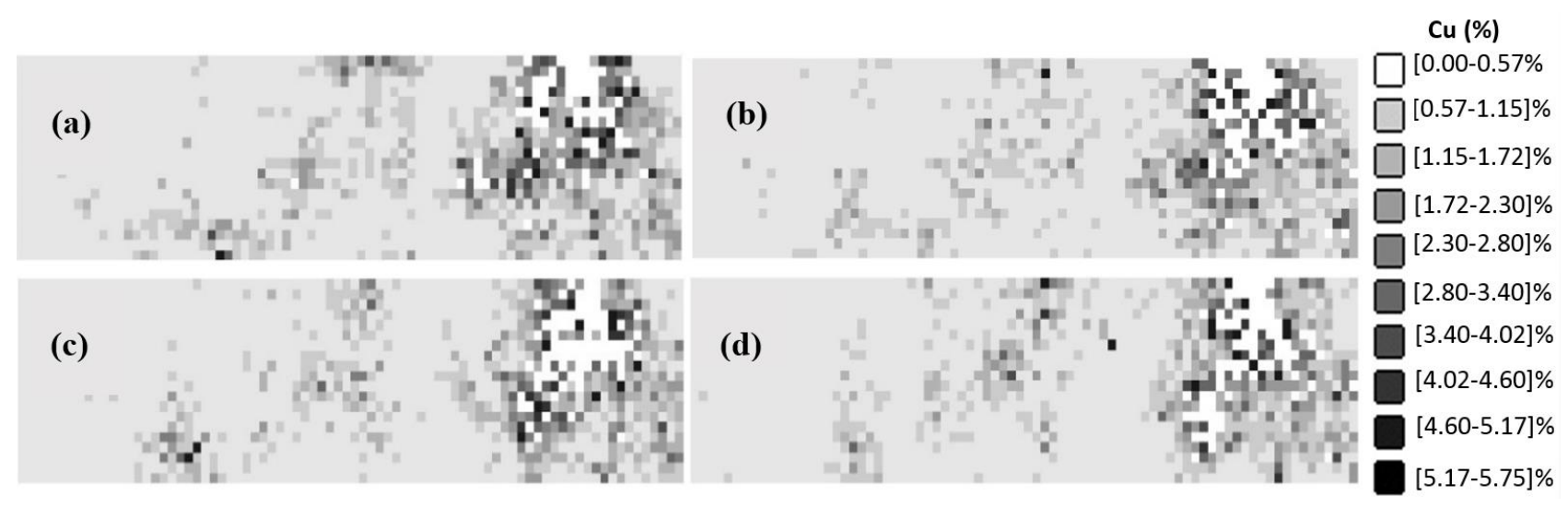

Figure 5 Horizontal section of grade block model, in $N 23^{\circ} \mathrm{W}$ direction at (a) $\mathrm{Y}=223245$; (b) $\mathrm{Y}=223250$; (c) $Y=223255 ;$ and, (d): $Y=223260$

\subsection{Stope generation}

The mining method in this orebody is longitudinal stoping - a similar method to the method of sublevel stoping. In longitudinal stoping the direction of mining is the same as sublevel stoping (along the strike of the orebody in a longitudinal direction). This method is designed for orebodies with a thickness in the range of circa 5-20 m (Tatiya 2005). Determination of stope dimensions in these methods can, in most cases, be achieved by designing stopes with high vertical and short horizontal dimensions or stopes having short vertical and long horizontal dimensions (Villaescusa 2000).

For this study, stope dimensions are considered as $50 \times 20 \times 25 \mathrm{~m}$. As calculated by the computer program (SLO3D), 1,136 possible stopes were generated, of which 974 stopes had a positive value and 162 stopes had a negative value (Table 5).

Table 5 Summary of possible stopes generated

\begin{tabular}{lll}
\hline Parameter & & Value \\
\hline \multirow{2}{*}{ Number of possible stopes } & Positive value & 974.00 \\
& Negative value & 162.00 \\
\hline \multirow{3}{*}{ Grade (\%) } & Min & 0.20 \\
& Max & 1.76 \\
& Average & 0.83 \\
\hline \multirow{2}{*}{ SEV (USD) } & Min & $-867,419.14$ \\
& Max & $4,658,403.18$ \\
& Average & $1,2693,07.13$ \\
\hline \multirow{2}{*}{ Metal weight (tonne) } & Min & 129.60 \\
& Max & $1,120.00$ \\
& Average & 526.60 \\
\hline
\end{tabular}




\subsection{Stope layout optimisation}

After generation of all possible stopes, stopes with negative economic value were removed and all positive stopes imported as the input file in order to produce all combinations of the combined non-overlapping stopes through the algorithm (Section 3.3). A unique set of non-overlapping stopes containing 29 stopes was selected as the optimum solution, with a value of USD $37.05 \mathrm{M}$. Table 6 shows the summary of the stope layout optimisation step. Stope ID, Stope Dimension in $X, Y$ and $Z$ direction (XINC, YINC and ZINC), Stope Grade (percent), Stope Economic Value (SEV), Total Weight, Metal Weight and identifier of origin and last block of each stope within the optimum limit are shown in Table 7.

Table 6 Summary of stopes generated within optimum layout

\begin{tabular}{lll}
\hline Parameter & & Value \\
\hline Number of stopes & & 29 \\
\hline Total economic value (USD) & $37.05 \mathrm{M}$ \\
\hline \multirow{2}{*}{ Grade (\%) } & Min & 0.46 \\
& Max & 1.28 \\
& Average & 0.83 \\
\hline \multirow{2}{*}{ SEV (USD) } & Min & $49,579.30$ \\
& Max & $2,905,380.96$ \\
& Average & $1,277,587.73$ \\
Metal weight (gram) & Min & 296.50 \\
& Max & 815.20 \\
& Average & 527.60 \\
\hline
\end{tabular}


Table 7 Values of stopes in optimum solution

\begin{tabular}{|c|c|c|c|c|c|c|c|c|c|c|}
\hline \multirow{2}{*}{ No. } & \multirow{2}{*}{ Stope ID } & \multirow{2}{*}{ Grade (\%) } & \multirow{2}{*}{ SEV (USD) } & \multirow{2}{*}{$\begin{array}{l}\text { Metal } \\
\text { (tonne) }\end{array}$} & \multicolumn{3}{|c|}{ Origin block } & \multicolumn{3}{|c|}{ Last block } \\
\hline & & & & & $x$ & $\mathbf{Y}$ & $\mathbf{Z}$ & $x$ & $\mathbf{Y}$ & $\mathbf{Z}$ \\
\hline 1 & 1 & 0.81 & $1,273,906.816$ & 514.84 & 1 & 1 & 1 & 10 & 4 & 5 \\
\hline 2 & 6 & 0.79 & $1,244,680.488$ & 503.34 & 1 & 1 & 6 & 10 & 4 & 10 \\
\hline 3 & 11 & 1.01 & $2,070,867.724$ & 646.82 & 1 & 1 & 11 & 10 & 4 & 15 \\
\hline 4 & 80 & 1.04 & $1,999,699.462$ & 664.16 & 5 & 1 & 16 & 14 & 4 & 20 \\
\hline 5 & 161 & 0.94 & $1,561,925.662$ & 596.91 & 11 & 1 & 1 & 20 & 4 & 5 \\
\hline 6 & 166 & 0.65 & $549,999.2011$ & 415.59 & 11 & 1 & 6 & 20 & 4 & 10 \\
\hline 7 & 171 & 0.87 & $1,303,862.937$ & 555.62 & 11 & 1 & 11 & 20 & 4 & 15 \\
\hline 8 & 322 & 0.46 & $49,579.29928$ & 296.72 & 21 & 1 & 2 & 30 & 4 & 6 \\
\hline 9 & 330 & 0.69 & $900,844.0652$ & 441.21 & 21 & 1 & 10 & 30 & 4 & 14 \\
\hline 10 & 368 & 0.50 & $138,315.9739$ & 321.26 & 23 & 1 & 16 & 32 & 4 & 20 \\
\hline 11 & 481 & 1.13 & $2,283,708.359$ & 720.39 & 31 & 1 & 1 & 40 & 4 & 5 \\
\hline 12 & 486 & 1.10 & $2,188,453.484$ & 698.57 & 31 & 1 & 6 & 40 & 4 & 10 \\
\hline 13 & 491 & 1.23 & $2,699,146.127$ & 783.57 & 31 & 1 & 11 & 40 & 4 & 15 \\
\hline 14 & 560 & 1.14 & $2,318,046.64$ & 726.77 & 35 & 1 & 16 & 44 & 4 & 20 \\
\hline 15 & 641 & 0.71 & $781,486.3839$ & 451.44 & 41 & 1 & 1 & 50 & 4 & 5 \\
\hline 16 & 646 & 0.56 & $319,377.4155$ & 361.84 & 41 & 1 & 6 & 50 & 4 & 10 \\
\hline 17 & 651 & 0.77 & $1,079,351.313$ & 491.00 & 41 & 1 & 11 & 50 & 4 & 15 \\
\hline 18 & 752 & 0.63 & $549,862.6853$ & 401.61 & 47 & 1 & 16 & 56 & 4 & 20 \\
\hline 19 & 801 & 0.83 & $1,333,063.971$ & 527.70 & 51 & 1 & 1 & 60 & 4 & 5 \\
\hline 20 & 806 & 0.73 & $985,764.3348$ & 463.80 & 51 & 1 & 6 & 60 & 4 & 10 \\
\hline 21 & 811 & 1.06 & $2,220,607.588$ & 678.12 & 51 & 1 & 11 & 60 & 4 & 15 \\
\hline 22 & 944 & 0.57 & $375,454.2742$ & 362.59 & 59 & 1 & 16 & 68 & 4 & 20 \\
\hline 23 & 961 & 0.98 & $1,746,695.373$ & 623.21 & 61 & 1 & 1 & 70 & 4 & 5 \\
\hline 24 & 966 & 0.83 & $1,303,448.075$ & 531.93 & 61 & 1 & 6 & 70 & 4 & 10 \\
\hline 25 & 971 & 1.28 & $2,905,380.967$ & 815.62 & 61 & 1 & 11 & 70 & 4 & 15 \\
\hline 26 & 1104 & 0.90 & $1,475,802.093$ & 574.68 & 69 & 1 & 16 & 78 & 4 & 20 \\
\hline 27 & 1121 & 0.60 & $464,234.7939$ & 383.00 & 71 & 1 & 1 & 80 & 4 & 5 \\
\hline 28 & 1126 & 0.57 & $367,185.6118$ & 363.71 & 71 & 1 & 6 & 80 & 4 & 10 \\
\hline 29 & 1131 & 0.60 & $559,293.018$ & 383.96 & 71 & 1 & 11 & 80 & 4 & 15 \\
\hline
\end{tabular}




\section{Conclusion}

The geometry of the mining area in an underground operation is one of the most important issues and maximises the economic value of a project. The complexity of underground mining methods has discouraged the development of computer programs and most of these computer programs do not guarantee the optimal layout, especially in 3D space. In this paper, a new computer program (SLO3D) developed to optimise stope layout according to economic factors, cut-off grade and specified stope dimension, has been presented. Also, for large and complex problems, three strategies that have been added to a heuristic algorithm in order to save solution time, were presented. The implementation of SLO3D was applied to an actual copper mine located in southeast Iran that resulted in an optimised layout with 29 stopes within the orebody with a value of USD $37.05 \mathrm{M}$.

\section{References}

Alford, C 1995, 'Optimisation in underground mine design', Proceedings of the 25th International APCOM Symposium, The Australasian Institute of Mining and Metallurgy, Melbourne, pp. 213-218.

Alford, C, Brazil, M \& Lee, DH 2007, 'Optimisation in underground mining', in A Weintraub, C Romero, T Bjørndal \& R Epstein (eds), Handbook of Operations Research in Natural Resources, Springer, New York, pp. 561-577.

Ataee-Pour, M 2000, A Heuristic Algorithm to Optimise Stope Boundaries, PhD thesis, University of Wollongong, Wollongong.

Ataee-Pour, M 2005, 'A critical survey of the existing stope layout optimisation techniques', Journal of Mining Science, vol. 41, no. 5, pp. 447-466.

Bai, X, Marcotte, D \& Simon, R 2013, 'Underground stope optimisation with network flow method', Computers \& Geosciences, vol. 52, pp. 361-371.

Bai, X, Marcotte, D \& Simon, R 2014, 'A heuristic sublevel stope optimizer with multiple raises', Journal of the Southern African Institute of Mining and Metallurgy, vol. 114, no. 6, pp. 427-434.

Carwse, I 2001, 'Multiple pass floating stope process', Proceedings of the Fourth Biennial Conference: Strategic Mine Planning, The Australasian Institute of Mining and Metallurgy, Melbourne.

Cheimanoff, NM, Deliac, EP \& Mallet, JL 1989, 'GEOCAD: an alternative CAD and artificial intelligence tool that helps moving from geological resources to mineable reserves', in A Weiss (ed.), Proceedings of the 21st International Symposium on the Application of Computers and Operations Research in the Mineral Industry, The American Institute of Mining, Metallurgical, and Petroleum Engineers, Englewood, pp. 471-478.

Datamine 1995, Floating Stope Optimizer - User Guide, Mineral Industries Limited, pp. 1-20.

Grieco, N, \& Dimitrakopoulos, R 2007, 'Managing grade risk in stope design optimisation: probabilistic mathematical programming model and application in sublevel stoping', Mining Technology, vol. 116, no. 2, pp. 49-57.

Jalali, SE \& Ataee-pour, M 2004, 'A 2D dynamic programming algorithm to optimize stope boundaries', in M Hardygóra, G Paszkowska \& M Sikora (eds), Proceedings of the 13th Symposium on Mine Planning and Equipment Selection, A.A. Balkema, Rotterdam, pp. 45-52.

Jalali, SE, Ataee-pour, M \& Shahriar, K 2007a, 'Rigorous algorithms to optimise stope boundaries; capabilities, restrictions and applications', Proceedings of the Seventh International Scientific Conference: Modern Management of Mine Producing, Geology and Environmental Protection, International Multidisciplinary Scientific GeoConferences, Sofia, pp. 113-120.

Jalali, SE, Ataee-pour, M, Shahriyar, K \& Elahi-Zeyni, E 2007b, 'A computer program to optimize stope boundaries using probable stope algorithm', Iranian Journal of Mining Engineering, vol. 2, no. 3, pp. 7-14, (in Persian).

Jalali, SE, Ataee-pour, M, Shahriar, K, Elahi-Zeyni, E \& Nikbin, V 2016, 'Computer based optimisation of underground mining area', Journal of Civil \& Environmental Engineering and Science Technology, vol. 48, no. 4, pp. 475-489, (in Persian).

Jalali, SE \& Hosseini, H 2009, 'Optimisation of extraction range in underground mining using a Greedy algorithm', Journal of Science and Research in Mining Engineering, vol. 4 no. 9, pp. 1-11, (in Persian).

Johnson, TB \& Sharp, WR 1971, A Three-dimensional Dynamic Programming Method for Optimal Ultimate Open Pit Design, Bureau of Mines, US Department of the Interior, Washington.

Mirzaeian, Y \& Ataee-pour, M 2011, 'Optimisation of stope geometry using Piecewise linear function and MIP approach', Journal of Civil \& Environmental Engineering and Science Technology, vol. 43, no. 1, pp. 79-87, (in Persian).

O'Sullivan, D \& Newman, A 2015, 'Optimisation-based heuristics for underground mine scheduling', European Journal of Operational Research, vol. 241, no. 1, pp. 248-259.

Ovanic, J \& Young, DS 1995, 'Economic optimisation of stope geometry using separable programming with special branch and bound techniques', in HS Mitri (ed.), Proceedings of the Third Canadian Conference on Computer Applications in the Mineral Industry, McGill University, Montreal, pp. 129-135.

Ovanic, J \& Young, DS 1999, 'Economic optimisation of open stope geometry', in K Dagdelen (ed.), Proceedings of the 28th International APCOM Symposium, Colorado School of Mines, Golden, pp. 855-862.

Riddle, JM 1977, 'A dynamic programming solution of a block-caving mine layout', Proceedings of the 14th International Symposium on Application of Computers and Operations Research in the Minerals Industries, Society for Mining, Metallurgy and Exploration, New York, pp. 767-780. 
Sandanayake, DSS, Topal, E \& Asad, MWA 2015a, 'A heuristic approach to optimal design of an underground mine stope layout', Applied Soft Computing, vol. 30, pp. 595-603.

Sandanayake, DSS, Topal, E \& Asad, MWA 2015b, 'Designing an optimal stope layout for underground mining based on a heuristic algorithm', International Journal of Mining Science and Technology, vol. 25, no. 5, pp. 767-772.

Tatiya, RR 2005, 'Classification - stoping methods', in RR Tatiya (ed.), Surface and Underground Excavations, Taylor \& Francis Group, London, pp. 415-431.

Topal, E \& Sens, J 2010, 'A new algorithm for stope boundary optimisation', Journal of Coal Science and Engineering (China), vol. 16, no. 2, pp. 113-119.

Villaescusa, E 2000, 'A review of sublevel stoping', Proceedings of MassMin 2000, The Australasian Institute of Mining and Metallurgy, Melbourne, pp. 577-590. 